\title{
Target-defining features in a "people-present/ people-absent" discrimination task by pigeons
}

\author{
ULRIKE AUST and LUDWIG HUBER \\ University of Vienna, Vienna, Austria
}

\begin{abstract}
Aust and Huber (2001) demonstrated that in a people-present/people-absent discrimination task, pigeons actually attended to properties of the target (i.e., the human figure). The aim of the present effort was to specify what sort of information contained in the target was used for classification, as well as to investigate whether and in what way the target-defining features interacted. Six pigeons were trained in a go/no-go procedure to discriminate between color photographs characterized by the presence or absence of people. They were then presented with various types of test stimuli that contained some categoryrelevant features but lacked others. The results showed that properties related to target size and internal structure played an important role and that human silhouettes were insufficient for eliciting a people-present response. Furthermore, some properties of the human figure (e.g., hands/arms) made good predictors of the people-present category, whereas others (e.g., feet/legs or skin color) did not. Responses to test stimuli that belonged to the people-absent category but nevertheless contained some features normally typical for humans (e.g., nonhuman primates) provided evidence that various categoryrelevant features contributed to classification in an additive way. Taken together, the results suggest that the pigeons made use of a polymorphous class rule involving collections of differently weighted target features.
\end{abstract}

Herrnstein and Loveland (1964) were the first to show not only that category discrimination in birds was possible, but also that it was learned easily and generalized widely. They reported that their pigeons learned to discriminate between sets of complex, real-scene color photographs that were distinguished only by the presence of a human being in each member of one of the sets. Inspired by their pioneering study, a lively area of research into the issue of animal categorization has developed. So far, a substantial body of work has been conducted, confirming that pigeons (Aust \& Huber, 2001; Edwards \& Honig, 1987; Greene, 1983; Herrnstein, Loveland, \& Cable, 1976; Malott \& Siddall, 1972; Siegel \& Honig, 1970), as well as monkeys (D'Amato \& Van Sant, 1988; Schrier \& Brady, 1987), can easily acquire a people-present/people-absent discrimination task and can also show good transfer to novel instances.

However, the nature of the stimulus properties used for classification and the way in which they have been organized have hitherto received only scant attention. Rather as a side result, Herrnstein and Loveland (1964) reported that their pigeons sometimes failed on pictures of the peoplepresent category in which the human being was severely obscured. In turn, the birds occasionally classified pictures that contained objects frequently associated with people,

The research was supported by Grant P14175-BIO from the Austrian Science Foundation. Thanks are due Michaela Loidolt and Michael Pollirer for their assistance in the pigeon laboratory. Correspondence concerning this article should be addressed to L. Huber, Institute of Zoology, University of Vienna, Althanstrasse 14, 1090 Vienna, Austria (e-mail: ludwig.huber@univie.ac.at). such as cars or houses, as if they were members of the people-present category. Similar classification errors were reported for cebus monkeys (D'Amato \& Van Sant, 1988). For example, any nonperson slide that contained a red patch, such as half a watermelon or a flamingo, was likely to be classified as belonging to the people-present category. A straightforward interpretation of that finding may be that the feature of a red patch was used to classify the photographs, presumably because it was common to many faces (see Pearce, 1997, p. 120). In Aust and Huber (2001), we found some indication that our pigeons used color and local properties as classification cues in the discrimination of people versus nonpeople images. Through the presentation of gray-scale stimuli, it was indicated that color was important for the classification of novel stimuli and the recognition of familiar ones. Classification of scrambled stimuli was based on small and local features, rather than on global ones. However, hardly anything could be told from the results about the importance of specific stimulus properties or about the extent of the internal list of target-defining features formed by the pigeons. A similar state of uncertainty holds for the structure of that feature list - that is, the way in which the target-defining features were organized.

One reason that few attempts have been made to take a close look at the content and the structure of feature lists formed in a people-present/people-absent discrimination task may lie in the fact that in experiments in which natural stimuli are employed, the features that actually correlate with response rates often prove difficult to identify (Watanabe, Lea, \& Dittrich, 1993). Furthermore, the mul- 
titude of features that may be involved makes a comprehensive investigation difficult. However, a promising starting point could be the analysis of misclassifications, such as those reported by Herrnstein and Loveland (1964) and D'Amato and Van Sant (1988). First, classification "errors" are a useful source of information regarding the nature of the internal representation, since persistent reliance on irrelevant features would clearly argue against an accurate, subtly differentiated target representation (D'Amato \& Van Sant, 1988). By inference, different classifications of the same images by different species may reveal differences in their target representations. For instance, in several experiments, pigeons were found to respond accurately to what, to the human observer, were atypical instances of an experimenter-defined category (Herrnstein \& de Villiers, 1980; Herrnstein et al., 1976; Roberts \& Mazmanian, 1988). Such results have raised serious doubts about the equivalence of target representations built by humans and pigeons (see also McIlvane, Serna, Dube, \& Stromer, 2000). Second, misclassifications of pictures whose feature content has been varied in a systematic way permit conclusions about the relevance of particular features for classifying pictures according to an experimenter-defined rule.

For those reasons, we chose an approach that hinged on the analysis of classification "errors" in order to gain insight into the content and structure of the target representation formed by pigeons in a people-present/people-absent discrimination task. In particular, the focus of the present investigation was the following questions. (1) Which target properties are relevant for classifying novel pictures as instances of the people-present category? (2) Do pigeons use only a few salient features, or do they rely on a complex compound of diverse features? (3) Are the targetdefining features equal in significance, or are they differently weighted? (4) Are they independent from each other or interrelated? Or to put it differently, is the salience of individual features influenced by contextual informationthat is, do they interact? In an effort to address these issues, we conducted three tests in which pigeons were presented with pictures whose feature content had been systematically varied; that is, they contained some category-specific features but lacked others. Response rates to such stimuli permitted conclusions about the relevance of specific stimulus properties and the role of context and interrelations among individual target-defining features.

The pigeons initially learned to discriminate between people-present and people-absent pictures, whose number was increased across two training phases, prior to their transfer to the test procedure. Test 1 focused on potential limitations of what the pigeons accepted as a target (i.e., a person) by presenting them with pictures that contained human figures that were impoverished in some respect, relative to the regular training stimuli. As a consequence, the test stimuli were-in our judgment-more difficult to recognize as members of the people-present category than were the training stimuli. The extent to which this modification affected response rates allowed us to draw con- clusions about the relevance of certain target properties for classification.

Test 2 was designed to investigate the relative importance of various target elements. In particular, we examined whether isolated parts of the human figure were sufficient for classification and whether particular body parts were more important for classification than others. Therefore, the pigeons were shown pictures containing isolated parts of a human figure - that is, with body parts that were detached from their usual context.

Test 3 focused on the breadth of the target representation formed by the pigeons. If the target representation was rather coarse - that is, if the target-defining features were shaped roughly and fuzzily and were independent of each other - this would lead to a rather tolerant principle of inclusion. Consequently, pictures of nonhumans should also qualify for class membership if their constituting features were - maybe even just vaguely - similar to those of "true" humans. By contrast, with a more subtly differentiated target representation, the pigeons should be more inclined to reject these pictures as targets. To test those alternatives, the pigeons were presented with pictures of nonhuman creatures and objects containing, in the experimenters' view, some features typical for human beings but lacking others.

\section{METHOD}

\section{Subjects}

We employed 6 pigeons of a local Austrian race (Columba livia, "Strasser") as experimental subjects. Four pigeons had already participated in previous experiments on the discrimination of the presence and absence of people (Aust \& Huber, 2001). In addition, 2 birds that were completely naive to that kind of task (but had served as subjects in other experiments on visual categorization; e.g., in Troje, Huber, Loidolt, Aust, \& Fieder, 1999) were used. Food was provided only during and immediately after the experimental sessions. Water and grit were freely available in the aviary. The birds were maintained at about $90 \%$ of their free-feeding weights.

\section{Stimuli}

The training procedure initially included a total of 400 stimuli. From Test 2 onward, the range was extended to 560. The pictures were taken from the database of the Photodisc Starter Kit and the Photodisc collection (watermarked; www.photodisc.com). Half of the stimuli showed one or more people, whereas the other half was devoid of humans or parts thereof. The pictures included a wide variety of settings, and the depicted persons varied in number, identity, sex, race, age, size, apparel, position within the picture, posture, and the area of the picture that they occupied. Examples of training stimuli are shown in Figure 1A.

For the tests, different types of probe stimuli were created. By type, we mean a specific kind of modification, as compared with regular instances of the people-present class. We originally created 80 test stimuli of 5 types in Test 1, 150 test stimuli of 6 types in Test 2, and 400 test stimuli of 16 types in Test 3 . Because it was not obvious what stimulus aspects the pigeons might attend to, we initially tested a wide variety of properties chosen and grouped in a rather intuitive way. Later, we decided to discard stimulus types that, on closer scrutiny, did not appear to be very meaningful. Three types from Test 1, 1 from Test 2, and 10 from Test 3 were discarded and are not included in the present report for the following reasons. Some had been built according to criteria that were probably too sophisticated, 
A
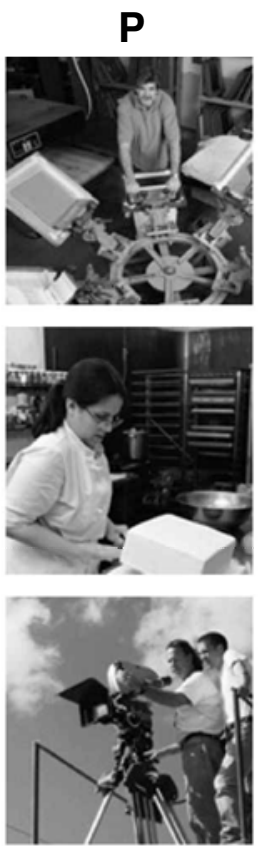
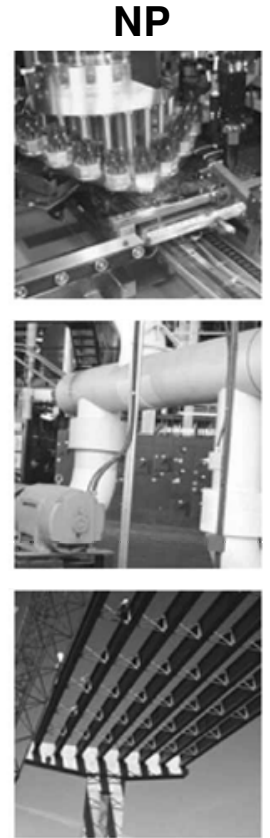

B
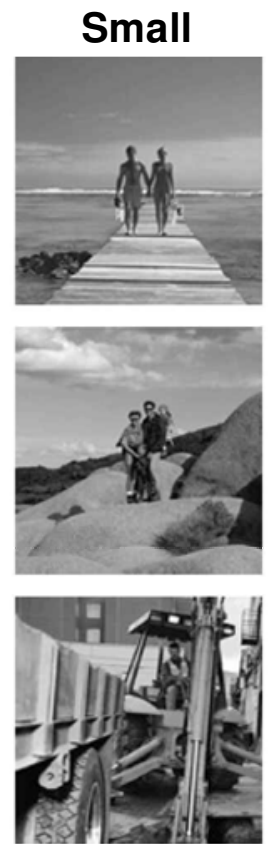

Silhouette
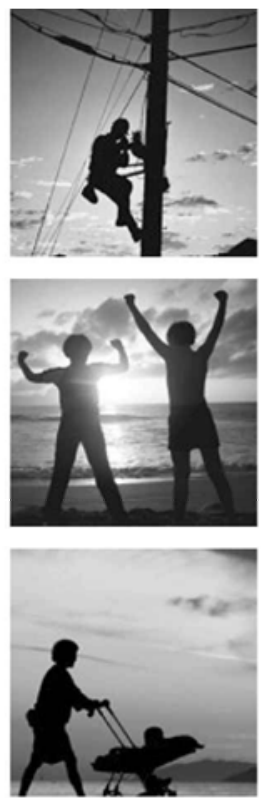

Figure 1. (A) Selection of training stimuli of the people-present (P) and the people-absent (NP) categories. (B) Selection of the two ty pes of test stimuli presented in Test 1: small (person very small) and silhouette (person present as silhouette only). All the stimuli were presented in color. A sample of training stimuli and the complete collection of test stimuli, as well as of the stimuli used in Aust and Huber (2001), can be seen in color at Ludwig Huber's homepage (available at http://www.univie. ac.at/zoology/theo/ludwig.htm).

anthropomorphic, or far-fetched. Other types, chosen on the assumption that the depicted objects were correlated with human figures in the training stimuli (thus providing a spurious basis for classification), were discarded when we found that the correlation was not as strong as we had previously thought. We also omitted stimuli that, on closer inspection, were found to belong to more than 1 type, in order to avoid overlaps. Also some types were discarded because they were very similar to others and, thus, more or less redundant.

The test stimuli presented in Test 1 showed human figures that, however, deviated in some respect from those contained in the peoplepresent training stimuli. The two types included in the present report were the following: small, 20 pictures showing people that were clearly smaller than those employed during training, and silhouette, 16 pictures depicting people in silhouettes only. Examples of these two types of test stimuli are shown in Figure 1B. In addition to the test stimuli, 80 novel regular instances of the people-absent class were presented as well.

In Test 2, 125 novel pictures that contained isolated parts of human figures were used as test stimuli. They were created in two different ways. Some consisted of people-present pictures from which the human figure, except for the body part to be examined, had been removed. For others, the respective body part was taken from a peoplepresent picture and was mounted onto a people-absent picture. By varying the method of creating the test stimuli in this fashion, we tried to minimize the risk of categorization's being influenced by a certain type of artifact caused by picture manipulation. In the former case, such artifacts may, for example, arise from incomplete removal of the person. In the latter case, mounting parts of a person onto another background may give rise to conspicuous contrasts between target and background or to inconsistencies in light. Apart from the body part to be examined, none of the test stimuli contained any other people or parts thereof. Twenty-five stimuli of each of the following five types were presented: hands, pictures showing human hands and, in most cases, also parts of the arms; head, stimuli displaying human heads, including the hair and, sometimes, the neck; trunk, pictures of human torsos, including extremities (i.e., bodies without heads); feet, pictures of human feet, mostly including parts of the legs; and skin, pictures containing patches of human skin that were of variable size and shape. Examples of these test stimuli are displayed in Figure 2A. In addition to the test stimuli, 30 novel stimuli that were regular instances of the two stimulus classes (15 people-present and 15 people-absent) were interspersed with training contingencies as well.

In Test 3, 208 test stimuli belonging to six different types were presented. Pseudohuman stimuli consisted of 20 pictures of artifacts representing humans (e.g., dolls, scarecrows, or snowmen). The 32 primate pictures showed nonhuman primates. The mammal stimuli included 53 pictures of nonprimate mammals, and the 33 bird pictures showed exemplars of various bird species. Furthermore, to investigate the effect of additivity of features, we presented 56 pictures showing items of apparel in isolation (clothes isolated), as well as 14 pictures of clothes being worn by animals (clothes worn). Examples of these test stimuli are shown in Figure 2B. In addition to the test stimuli, 80 novel regular stimuli, 40 from each training class, were interspersed with training contingencies ( $\operatorname{trnP}$ and $\operatorname{trnNP}$ ).

\section{Apparatus}

The birds entered an experimental indoor chamber (Skinner box) from an outdoor aviary compartment through a passageway system (details in Huber, 1994). The interior size of the wooden chamber was 
A
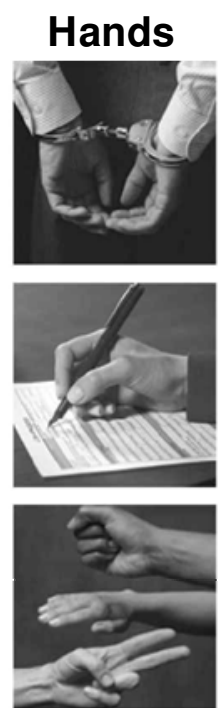

B
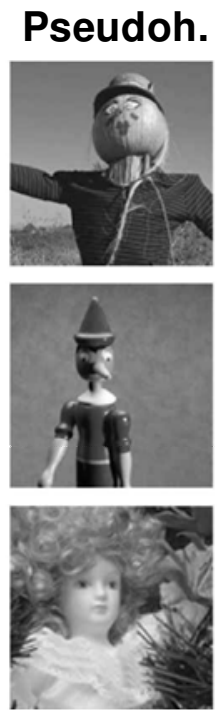
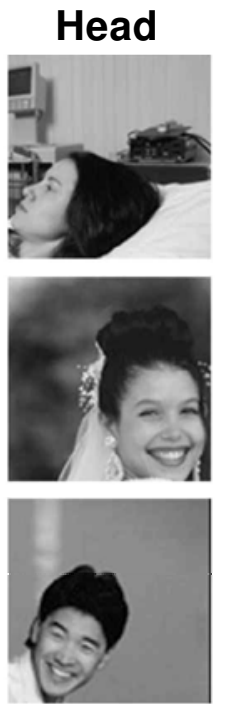

\section{Primate}
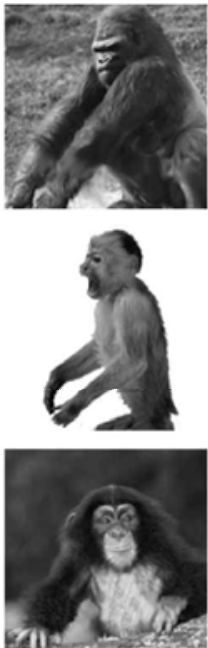

Trunk
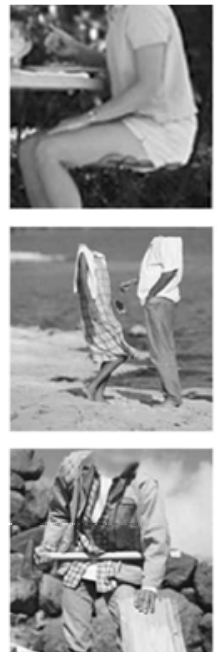

Mammal
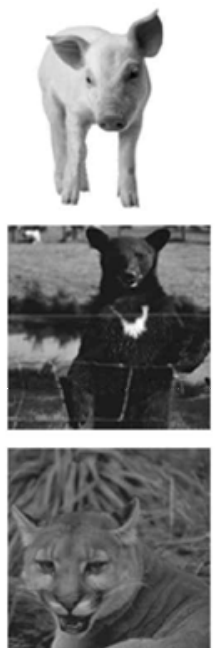
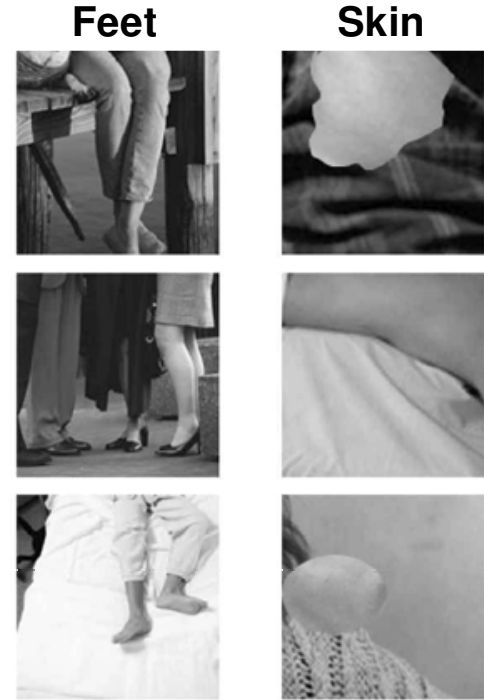
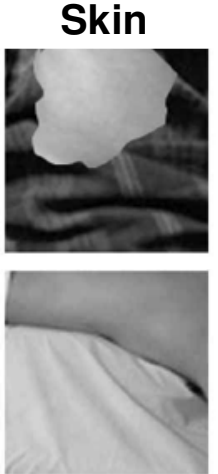

\section{Clothes isol. Clothes worn}
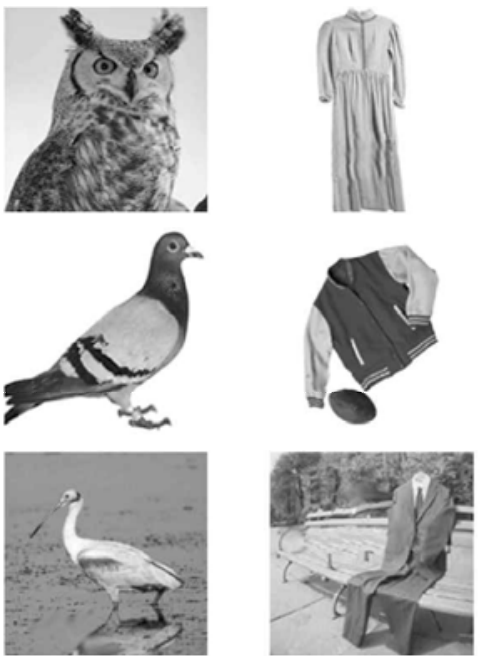
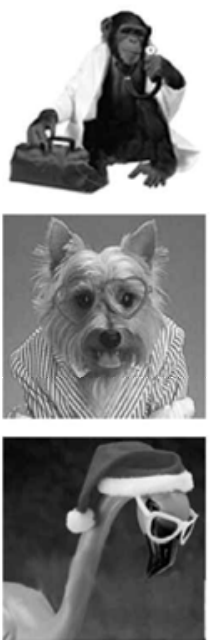

Figure 2. (A) Selection of the five types of test stimuli presented in Test 2: hands/arms (hands, mostly with parts of the arms); heads (faces plus hair, sometimes with neck); trunks plus extremities (bodies without heads); feet/legs (feet, mostly with parts of the legs); skin (patches of variable size and shape, showing human skin). (B) Selection of the six types of test stimuli presented in Test 3: pseudohuman (pseudoh.; artifact representing a human being), nonhuman primate, nonprimate mammal, bird, clothes in isolation (clothes isol.), and clothes worn by animals.

$50 \times 30 \times 40 \mathrm{~cm}$. In the center of the front panel was a clear perspex pecking key (5-cm diameter, ENV-125M, MED Associates, Georgia, VT). Directly below the key was a $6 \times 6 \mathrm{~cm}$ aperture for a $28-V$ DC solenoid-activated hopper of a grain feeder (ENV-205M). A hopper light illuminated the receptacle area whenever grain was accessible. Except for a dark intertrial interval that preceded stimulus presentation, the chamber was weakly illuminated throughout the experiment by a 2-W houselight (ENV-215) located in the rear part of the chamber. Stimulus presentation was accomplished with a Pentium PC running a Delphi program that selected the patterns according to a prespecified sequence. The stimuli were presented on a 15-in. (38-cm-diagonal) CRT monitor (Panasonic PanaSync 4G) at a distance of $5 \mathrm{~cm}$ behind the pecking key. They were presented at a size of $128 \times 128$ pixels and at a resolution of $1,024 \times 768$ pixels, producing a $45 \times 45 \mathrm{~mm}$ picture on the monitor. The MED for Windows behavioral control package, which was installed on a separate PC, was used to control events in the operant chamber, to signal stimulus onset and offset to the presentation PCs, and to register responses.

\section{Procedure}

All 6 pigeons were familiar with the experimental chamber and the procedure from the outset of the experiment, because they had already served as subjects in previous experiments (e.g., in Troje 
et al., 1999). Thus, they were immediately subjected to the training procedure. Each bird belonged to one of two experimental groups. For one group (Group P), the stimuli containing at least one person (Class $\mathrm{P}$ ) were designated positive, and the stimuli that did not show any people (Class NP) were designated negative. These contingencies were reversed for the other group (Group NP). The 4 birds from Aust and Huber (2001) had already been assigned in equal numbers to each group. Each group was also assigned 1 additional bird that was completely naive to the task.

We used a standard go/no-go procedure (Vaughan \& Greene, 1984; see also Herrnstein \& Loveland, 1964; Herrnstein et al., 1976), which required the pigeons to peck in the presence of positive stimuli and to refrain from pecking in the presence of negative stimuli. Each bird ran one session per day, 5 days a week, with each session consisting of the presentation of 40 stimuli, 20 positive and 20 negative. The entire sequences were quasi-random insofar as they never contained more than 3 positive or negative stimuli in immediate succession, and the 1st stimulus of each session was always a positive one. Pecks were counted and registered for later data analysis only during the first $10 \mathrm{sec}$ of a trial. During the subsequent variable interval (VI; mean, $10 \mathrm{sec}$; range, 1-20 sec) it was unimportant whether or not the pigeons pecked, since pecks were not registered. After the VI was terminated, pecks were registered again, not for later data analysis, but in order to determine whether the response requirement for positive or negative trials was met. On positive trials, two pecks emitted within $2 \mathrm{sec}$ (after the VI) resulted in $5 \mathrm{sec}$ of food access. On negative trials, each response emitted to a negative stimulus prolonged stimulus presentation, which was terminated only after no further responses had occurred within $8 \mathrm{sec}$. No food was delivered on negative trials. The image remained visible throughout the entire trial. Each trial was followed by an intertrial interval, a dark phase of $4 \mathrm{sec}$ that signaled the forthcoming stimulus presentation.

The range of training stimuli was extended in three successive steps. (1) In Training Phase 1, a total of 320 stimuli was presented. Each session contained 10 stimuli from the 80 -stimulus training set used in Aust and Huber (2001), 10 stimuli from the 80-stimulus test set used in Aust and Huber (2001, Experiment 1), and 20 stimuli from a pool of 160 that had not been presented before. Each of the 16 Phase 1 sessions thus involved two presentations of each stimulus. (2) In Training Phase 2, the 320 stimuli from Phase 1 were used, plus 80 novel stimuli that were introduced at a rate of 8 per session. Each stimulus was presented only once during the 10 Phase 2 sessions. These 400 stimuli constituted the pool from which the training stimuli presented in Test 1 were selected. (3) From Test 2 onward, the test stimuli, as well as the novel stimuli of Class NP introduced in Test 1, were also integrated into the training set (without any further training phase), which extended the range of training stimuli to a total of 560 .

Test stimuli were interspersed at a rate of 5 (Test 1) or 10 (Tests 2 and 3 ) per session into ordinary training sequences, thereby replacing an equal number of training stimuli. The training stimuli were arbitrarily selected from among the 400 (Test 1) or 560 (Tests 2 and 3) training stimuli. In Test 1 , the test stimuli were presented with training (reinforcement) contingencies because they contained human figures and, so, class membership, as determined by the class rule implemented by the experimenter (people-present/ people-absent), was unambiguous. By contrast, class membership of the test stimuli in Tests 2 and 3 was often arguable. For that reason, they were presented in extinction. On extinction trials, the stimulus terminated after $10 \mathrm{sec}$.

In addition to the test stimuli, 80 novel stimuli that were regular instances of Class NP were also interspersed with training contingencies (trnNP) at a rate of 5 per session in Test 1 . This was done to provide equal numbers of novel stimuli of Class $\mathrm{P}$ (the test stimuli) and of Class NP (trnNP) and in order to prevent the pigeons from classifying all stimuli recognized as unfamiliar as members of Class P. Similarly, in Tests 2 and 3, the pigeons were prevented from coming to realize that it was irrelevant whether or not they responded to stimuli recognized as unfamiliar by including 1 novel stimulus of Class $\mathrm{P}$ and 1 of Class NP with ordinary training contingencies (trnP and trnNP) into each session. Performances on the novel positive and negative training stimuli presented in Test 3 were also used as reference values with which test performances achieved in the three tests were compared. Sixteen sessions were required to complete Test 1,15 for Test 2 , and 40 for Test 3 (including presentation of those stimulus types that did not enter the present report). Table 1 gives an overview of the complete experimental design.

\section{Statistics}

To bypass the problems that small sample sizes pose for statistical analyses based on between-group comparisons, performance was assessed separately for each bird. Training performance was assessed as rho values $(\rho)$, a nonparametric statistic introduced by Herrnstein et al. (1976; see also Aust \& Huber, 2001). That measure was chosen to make the results comparable with those by Herrnstein and Loveland (1964) and Aust and Huber (2001, Experiment 2), which were based on ranked data as well. Assessment of the test results was based on the mean standardized response rate. This is a more demanding measure than the $\rho$ value and was obtained by dividing the absolute number of pecks emitted on each trial of a session (both training and test trials) by the average peck rate of the respective session, as measured on trials with training contingencies only.

\section{Results}

Figure 3 illustrates the results of the two training phases for each of the 6 pigeons. The 4 experienced birds are indicated by (e), the two naive ones by (n). The results are summarized on a session-by-session basis as $\rho$ values. As was expected, performance of the 2 naive birds started at or below chance levels in Training Phase 1 but increased in the course of training. In Training Phase 2, the increasing number of stimuli did not disrupt the performances of the 4 experienced birds who, in fact, mastered Training Phase 2 almost without decrement. Although performances by the naive birds were disrupted at the start of Training Phase 2, by the end of this phase Bird T62-PP (n) had completely caught up with the experienced birds of Group P. Likewise, the performance of Bird T60-NP (n) had at least reached a statistically significant level of discrimination by the end of Phase 2. Therefore, we no longer distinguished between experienced and naive pigeons in the subsequent tests. Figure 3 suggests that for the experi-

\section{Table 1}

Overview of the Experimental Design

\begin{tabular}{lrrrrrll}
\hline \multicolumn{1}{c}{ Condition } & sess & tr & te & te/sess & te cont & \multicolumn{1}{c}{ trn } & trn/sess \\
\hline Training Phase 1 & 16 & 320 & - & - & - & $160 \mathrm{P} / 160 \mathrm{NP}$ & variable \\
Training Phase 2 & 10 & 400 & - & - & - & $80 \mathrm{P} / 80 \mathrm{NP}$ & $4 \mathrm{P} / 4 \mathrm{NP}$ \\
Test 1 & 16 & 400 & 80 & 5 & tr & $80 \mathrm{NP}$ & $5 \mathrm{NP}$ \\
Test 2 & 15 & 560 & 30 & 10 & te & $15 \mathrm{P} / 15 \mathrm{NP}$ & $1 \mathrm{P} / 1 \mathrm{NP}$ \\
Test 3 & 40 & 560 & 400 & 10 & te & $20 \mathrm{P} / 20 \mathrm{NP}$ & $1 \mathrm{P} / 1 \mathrm{NP}$ \\
\hline
\end{tabular}

Note-Number of sessions, trial composition, and reinforcement contingencies in the various phases of the experiment. sess, number of sessions in the respective experimental phase; tr, number of training stimuli (except trnP and trnNP); te, number of test stimuli; te/sess, number of test stimuli presented by session; te cont, contingency of the test stimuli (tr, reinforced; te, nonreinforced); trn, number of novel regular instances of Class P and of Class NP; trn/sess, number of novel regular instances introduced in each session; $\mathrm{P}$, stimulus of Class $\mathrm{P}$ (people present); NP, stimulus of Class NP (people absent). 


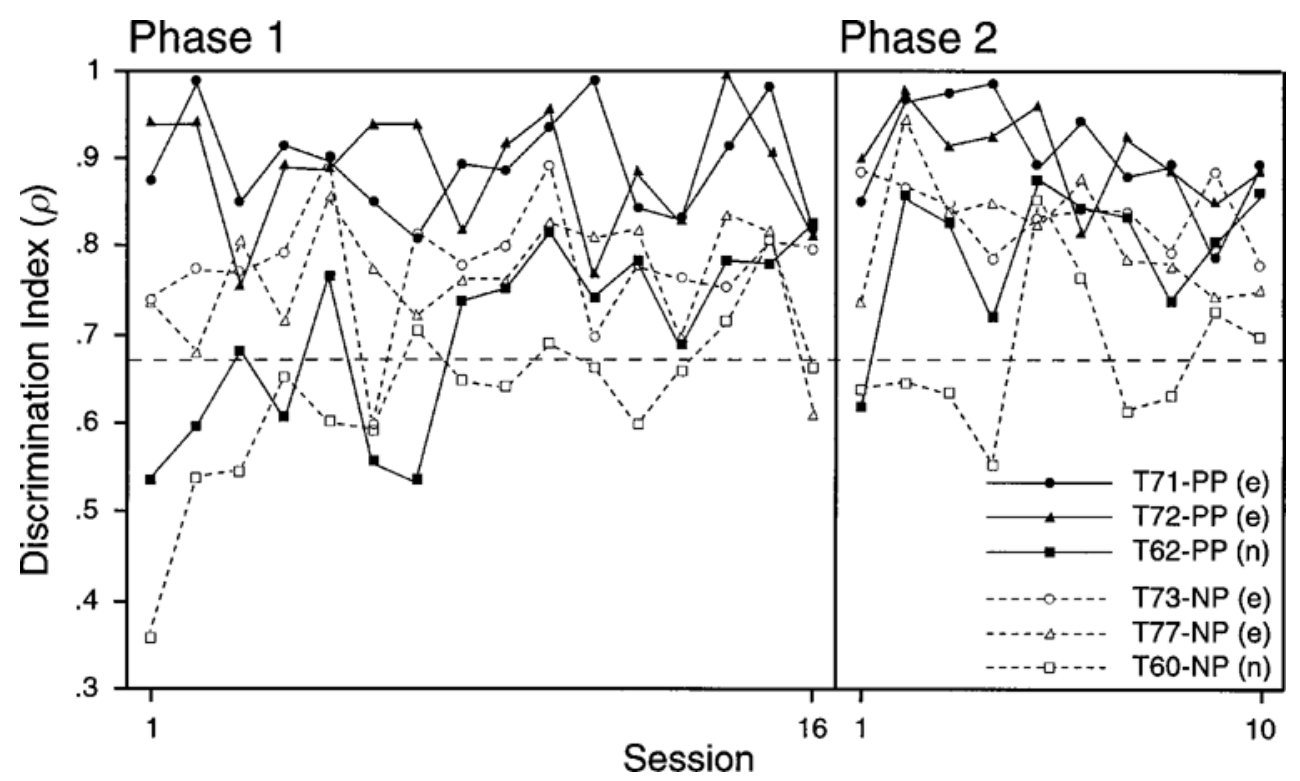

Figure 3. Performance of the 4 experienced pigeons (e) and of the 2 naive birds (n) in the two training phases, shown on a session-by-session basis as $\rho$ values. The dashed line indicates the limit of significance (.680).

enced birds, Group P performed consistently better than Group NP, and there appeared to be a similar discrepancy in performance for the naive birds.

Figure 4 compares the results obtained for the individual types of test stimuli with those obtained for the 40 novel stimuli of each class, which were presented with training contingencies in Test 3 (trnP and trnNP). The results are displayed as box plots, which give the distribution of mean standardized pecks performed in response to each set of test stimuli. Gray areas indicate confidence interval bounds around the median. Each box comprises the data of the 3 birds belonging to the same group. The most interesting results that can be derived from Figure 4 are as follows.

In Test 1, both small and silhouette stimuli led to a considerable decline in performance, as compared with regular instances of Class $\mathrm{P}(\operatorname{trn} \mathrm{P})$. The gray areas of the respective boxes overlapped with those for trnNP, but not with those for trnP in both groups, indicating significant deviations from the latter, but not from the former. Thus, the small and silhouette stimuli were classified as regular members of Class NP.

In Test 2, the gray areas for hands overlapped with those for trnP in both groups, whereas those for feet and skin overlapped with trnNP. In Group P (top panel), there was also an overlap between the gray areas of the boxes for trunk and trnP. The gray area of the head box did not overlap with either reference value in both groups. In short, hands were regularly classified as members of the peoplepresent category, whereas feet and skin were assigned to the people-absent category. Head and trunk were classified differently, depending on the individual bird.
For Test 3, Figure 4 indicates that, on the whole, pseudohumans gave rise to more misclassifications in Group P than did animals (i.e., primates, mammals, and birds). In other words, the pseudohuman stimuli were most likely to generate a person-present response. Response rates declined roughly as a function of decreasing supposed similarity of the depicted objects or animals with humans (pseudohuman $>$ primate $>$ mammal and bird). However, these differences turned out to be mainly due to the behavior of 1 pigeon and thus did not constitute a real trend.

We also investigated whether the presence of animals (which contained at least some features otherwise typical for humans) combined with clothes (clothes worn) increased the likelihood of a stimulus's being classified as member of Class $\mathrm{P}$, as compared with the presence of only one of these components (either animals or clothes). We therefore compared the results of clothes worn, clothes isolated, and those of pictures showing animals without clothes. The latter category incorporated the data obtained for primate, mammal, and bird into one single type of test stimuli, which we called animal. Pictures showing animals wearing clothes (clothes worn) were more likely to elicit classification errors (a person-present response) than were pictures showing either animals without clothes (animal) or items of apparel shown in isolation (clothes isolated).

In what follows, the results summarized above are described in more detail. The performance of each bird was assessed by comparing the mean standardized response rate obtained for each test stimulus type with that obtained for trnP and trnNP by means of two-sample $t$ tests. Table 2 gives the mean standardized peck rates for the different 
GROUP P

Regular

$40 \quad 40$

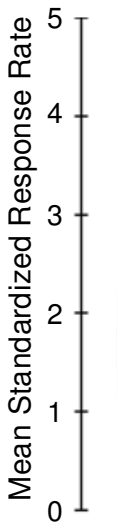

$\operatorname{trnP} \operatorname{trnNP}$
Test 1

2016
Test 2

$25 \quad 25 \quad 25 \quad 25 \quad 25$
Test 3

$\begin{array}{lllllll}20 & 32 & 53 & 33 & 56 & 14 & 118\end{array}$

$\circ$

GROUP NP

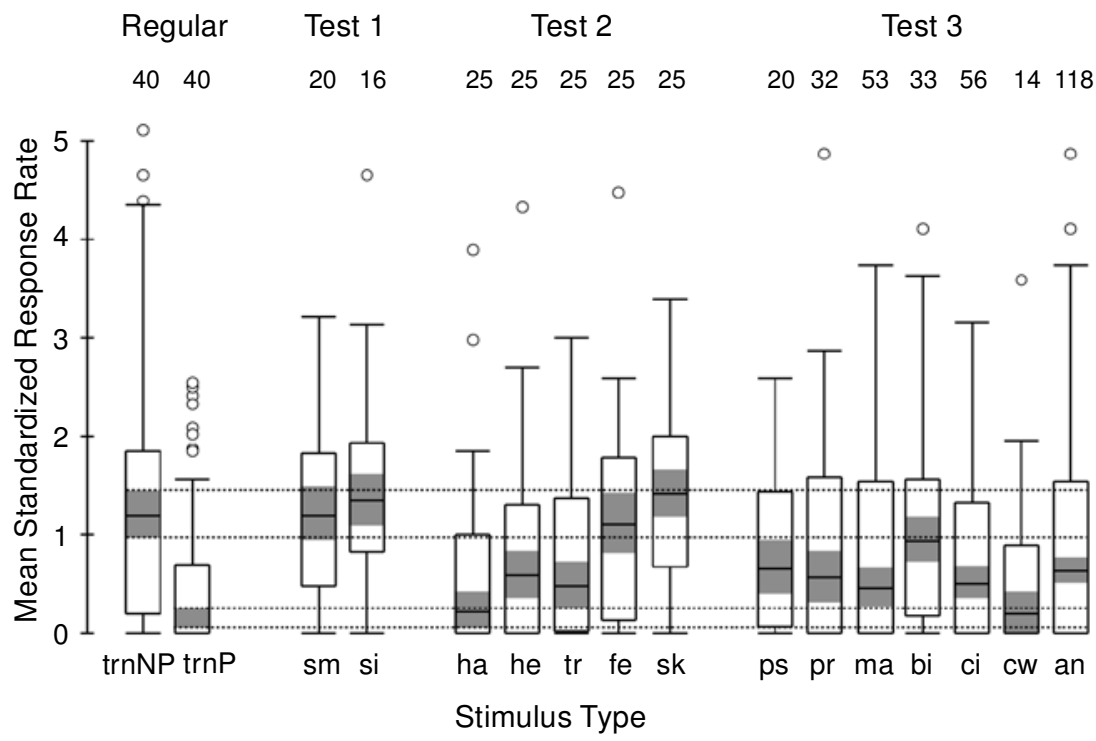

Figure 4. Performance on the various types of test stimuli shown separately for Groups $\mathbf{P}$ and NP and in comparison with performance on the novel training stimuli introduced in Test 3 (trnP and trnNP) as box plots. The central box depicts the middle half of the data between the 25 th and the 75 th percentiles. The horizontal line across the box marks the median value in the data. The whiskers extend to the 90th percentile and thus depict the extent of the "main body" of the data. The circles represent data values between 1.5 and 3 times the interquartile range above the 75 th percentile. The shaded areas indicate confidence interval bounds around the median. If two gray boxes fail to overlap, the corresponding medians are discernably different at approximately the $0.05 \%$ significance level. The dashed horizontal lines prolong the borders of the gray areas of the box plots for $\operatorname{trn} P$ and $\operatorname{trnNP}$ to make overlaps more obvious. Means were taken across the pigeons of each group. Test stimuli of Test 1: sm, small; si, silhouette. Test stimuli of Test 2 : ha, hands; he, head; tr, trunk; fe, feet; sk, skin. Test stimuli of Test 3: ps, pseudohuman; pr, primate; ma, mammal; bi, bird; ci, clothes isolated; cw, clothes worn; an, animal (no separate type, but mean taken across pr, ma, and bi).

types of test stimuli. Response tendencies-that is, biases toward the one or the other class, as derived from the results of the $t$ tests - are indicated by font. Boldface type indicates stronger deviations from trnNP than from trnP (bias toward Class P), italic type indicates stronger deviations from trnP than from trnNP (bias toward Class NP), and roman type indicates roughly equal deviations either from both trnP and trnNP or from neither. 
Table 2

Overview of the Results of Tests 1,2 , and 3

\begin{tabular}{|c|c|c|c|c|c|c|c|c|c|c|c|c|c|c|c|c|}
\hline \multirow[b]{2}{*}{ Bird } & \multicolumn{2}{|c|}{ Training } & \multicolumn{2}{|c|}{ Test 1} & \multicolumn{5}{|c|}{ Test 2} & \multicolumn{7}{|c|}{ Test 3} \\
\hline & $\operatorname{trn} P$ & $\operatorname{trnNP}$ & $\mathrm{sm}$ & si & ha & he & $\operatorname{tr}$ & fe & sk & ps & $\mathrm{pr}$ & $\mathrm{ma}$ & bi & ci & $\mathrm{cw}$ & an \\
\hline T71-PP & 1.73 & 0.47 & 0.82 & 0.37 & 1.29 & 0.93 & 1.35 & 0.80 & 0.67 & 0.98 & 0.98 & 0.67 & 0.93 & 0.78 & 0.77 & 0.83 \\
\hline T72-PP & 1.62 & 0.62 & 1.02 & 0.82 & 1.27 & 1.10 & 1.47 & 0.78 & 0.68 & 1.38 & 0.98 & 0.93 & 0.82 & 0.99 & 1.60 & 0.91 \\
\hline T62-PP & 1.87 & 0.63 & 0.80 & 1.06 & 1.15 & 1.34 & 1.05 & 0.71 & 0.73 & 0.81 & 0.64 & 1.00 & 0.83 & 0.71 & 1.06 & 0.85 \\
\hline T73-NP & 0.59 & 1.08 & 1.10 & 1.20 & 0.36 & 0.70 & 0.82 & 0.96 & 1.40 & 0.97 & 0.94 & 0.76 & 1.13 & 0.68 & 0.55 & 0.91 \\
\hline T77-NP & 0.44 & 1.31 & 1.08 & 1.58 & 0.68 & 0.91 & 0.76 & 1.09 & 1.34 & 0.76 & 1.11 & 0.81 & 0.95 & 0.90 & 0.56 & 0.93 \\
\hline T60-NP & 0.31 & 1.37 & 1.42 & 1.40 & 0.63 & 0.81 & 0.83 & 1.13 & 1.32 & 0.63 & 0.75 & 0.97 & 0.99 & 0.85 & 0.63 & 0.91 \\
\hline
\end{tabular}

Note-Mean standardized peck rates on the various types of probe stimuli in Tests 1,2, and 3, and on the novel regular stimuli introduced in Test 3 (trnP and trnNP). Response tendencies are indicated by type of font. (Tendency means that there were either significant deviations from only one class of training stimuli, or that performance deviated significantly from both classes, but more strongly from one than from the other.) Italic type highlights values that deviated more strongly from trnP than from trnNP (bias toward Class NP). Boldface type indicates stronger deviations from trnNP than from trnP (bias toward Class P). Values in roman type deviated roughly equally either from both trnP and trnNP or from neither. Judgments on deviations were based on the results of the $t$ tests. Test stimuli of Test 1: sm, small; si, silhouette. Test stimuli of Test 2: ha, hands; he, head; tr, trunk; fe, feet; sk, skin. Types of Test 3: ps, pseudohuman; pr, primate; ma, mammal; bi, bird; ci, clothes isolated; cw, clothes worn; an, animal (no separate type, but mean taken across pr, ma, and bi).

In Test 1, all 6 birds failed to recognize a depicted person as a target when it was very small. For no pigeon did we find any significant differences between the small stimuli and the reference stimuli of Class NP $(\operatorname{trnNP})$. By contrast, test performances deviated significantly from those on trnP [lowest value, Bird T77-NP; $t(29)=-2.60$, $p \leq .05]$. When the person was presented as a silhouette only, the results were even clearer. Performances of all 6 birds on silhouette stimuli did not differ from those of the trnNP stimuli but did differ significantly from those of the trnP stimuli [lowest value, Bird T62-PP; $t(49)=2.17$, $p \leq .05]$.

In Test 2, hands were classified as members of Class $\mathrm{P}$ in the case of 5 pigeons (the performance of the 6th bird was ambiguous). For those 5 pigeons, there were no significant differences between performances on the hands stimuli and those on the trnP stimuli, but there were significant deviations from the trnNP stimuli [lowest value, Bird T77-NP; $t(62)=2.65, p \leq .05]$. For the head stimuli, the $t$ tests revealed significant deviations from trnNP, but not from trnP (and thus classification as Class P), for 1 pigeon [T73-NP; $t(62)=2.27, p \leq .05]$ and significant deviations from trnP, but not from trnNP (and thus classification as Class NP), for 2 pigeons [lower value, Bird T60$\mathrm{NP} ; t(30)=-2.07, p \leq .05]$. Two birds did not show a clear preference for either class, and the remaining bird (T71-PP) showed a larger deviation from trnP than from trnNP (a tendency toward Class NP).

In the case of trun $k$ stimuli, $t$ tests revealed that 3 pigeons classified these stimuli as members of Class $\mathrm{P}$, with significant deviations from trnNP [lowest value, Bird T77NP; $t(62)=2.40, p \leq .05$ ], but not from trnP. Two other birds classified them as members of Class NP, with significant deviations from trnP only [lower value, Bird T62PP; $t(61)=2.11, p \leq .05]$. The performance of the remaining bird was ambiguous, with no significant deviations from either stimulus class. For the feet stimuli, 5 pigeons classified them as members of Class NP, with no significant deviations from performance on trnNP, but signifi- cant deviations from trnP [lowest value, Bird T60-NP; $t(31)=-3.62, p \leq .01]$. The performance of the remaining bird was ambiguous. Finally, skin stimuli were clearly classified as Class NP by all 6 birds, with significant deviations from trnP only [lowest value, Bird T62$\mathrm{NP} ; t(61)=2.90, p \leq .01]$.

Regarding Test 3, responding to the pseudohuman stimuli varied considerably across individuals without any obvious common thread. These test stimuli were classified as members of Class P by 3 birds, whose performances deviated significantly only from trnNP [lowest value, Bird T77-NP; $t(56)=2.37 ; p \leq .05]$, and as members of Class NP by 1 bird, whose performance deviated only from trnP [Bird T62-PP; $t(55)=2.79, p \leq .01]$. One bird did not show a significant preference for either class, and the remaining bird's performance deviated more strongly from trnP than from trnNP.

The primate stimuli were classified as Class NP by 4 birds, with performances deviating significantly from that on trnP only [lowest value, Bird T77-NP; $t(40)=-2.18$, $p \leq .05]$. The performances of the 2 remaining birds differed significantly from both classes. For the mammal stimuli, we found a significant preference for Class NP for 4 birds, with performances deviating from trnP only [lowest value, Bird T62-PP; $t(71)=2.52, p \leq .05]$. The performances of the remaining 2 birds were ambiguous. The bird stimuli were classified as members of Class NP by 4 pigeons, with performances deviating from trnP only [lowest value, Bird T62-PP; $t(68)=2.90 ; p \leq .01$ ]. The performances of the remaining 2 birds were ambiguous.

Clothes isolated stimuli were classified as members of Class NP by 4 birds, whose performances deviated significantly only from that on trnP [lowest value, Bird T60NP; $t(69)=-2.31, p \leq .05]$, and as Class $\mathrm{P}$ by 1 bird, whose performance deviated from trnNP only [Bird T73NP; $t(64)=2.54 ; p \leq .05]$. The performance of the 6th bird deviated from both types of reference stimuli, but more strongly from trnP. By contrast, pictures showing clothes worn by animals (clothes worn) were classified as 
Class $\mathrm{P}$ by 4 pigeons, whose performances deviated significantly only from trnNP [lowest value, Bird T60-NP; $t(26)=2.08 ; p \leq .05]$. One bird showed a preference for Class NP [Bird T71-PP; $t(31)=3.60 ; p \leq .01$ ], and the performance of 1 bird was ambiguous. Animal stimuli were mostly treated as members of Class NP, rather than of Class $P$. The performances of 3 pigeons deviated from that on trnP only [lowest value, Bird T73-NP; $t(83)=$ $-2.56, p \leq .05]$. Those of the other birds deviated from both trnP and trnNP, but clearly more strongly from trnP than from trnNP. A tendency of clothes worn stimuli to elicit more classification errors than animal or clothes isolated stimuli was found in 5 of the 6 birds. For 1 pigeon, differences between clothes worn and clothes isolated stimuli [Bird T72-PP; $t(26)=2.63, p \leq .05]$ and between animal and clothes worn stimuli [Bird T72-PP; $t(18)=$ $3.27, p \leq .01]$ were significant.

\section{DISCUSSION}

The 4 experienced pigeons mastered training without difficulty. For the 2 naive birds, training conditions were more demanding insofar as, at the onset of the experiment, they were unfamiliar not only with all 400 training stimuli, but also with the nature of the task per se. Nevertheless, performance of the naive pigeons, especially that of Bird T62-PP (n), improved in the course of training. Considering the large number of stimuli and the small number of repetitions, it seems reasonable to suggest that this increase in performance was due mainly to mechanisms beyond learning the individual stimuli and their contingencies by rote and storing them on a pixel-by-pixel basis in the form of exact internal copies.

The finding that the pigeons of Group P performed consistently better than the pigeons of Group NP during training confirmed similar observations made in a previous and closely related study on people-present/people-absent discriminations (Aust \& Huber, 2001). In that study, as well as in the present experiment, a feature-positive effect may have been at work, which means that discrimination was facilitated when the target appeared on positive trials (see, e.g., Bottjer \& Hearst, 1979; Edwards \& Honig, 1987; Hearst, 1978; Jenkins \& Sainsbury, 1969, 1970; Manabe \& Kawashima, 1982; Pace, McCoy, \& Nallan, 1980; Sainsbury, 1971; Sainsbury \& Jenkins, 1967).

Test 1 pointed to some limitations of the target representation formed by the pigeons. Target size was found to be important, which is in keeping with the findings of research on invariance and the effects of metric variations. Although pigeons have been shown to generalize to stimuli altered in size, those changes result in accuracy decrements, which depend on the degree of change in stimulus size (Herrnstein, 1985; Kirkpatrick-Steger, 2001; see also Huber $\&$ Aust, 2001). Since we found silhouettes to be insufficient for identifying a target as such, it appears that structural cues are crucial. Test 2 showed that some parts of the human figure were more important than others and, sometimes, even sufficient for people-present classification.
For instance, hands proved to be good predictors of Class $\mathrm{P}$, whereas feet and skin color did not. Unfortunately, the results of Test 3 were not as clearcut as those of the preceding tests. In some cases, peck rates were characterized by wide variations among individuals. On the other hand, we sometimes found consistent response biases across all or most pigeons, which were also reflected by the box plots but were statistically nonsignificant for the individual birds. Such a result certainly dictates caution in drawing any strong conclusions. Nevertheless, we found at least some indication that response rates to nonpeople stimuli depended on the amount of otherwise people-specific features contained in the pictures. These findings permit the following conclusions.

First, the results of Tests 2 and 3 confirm the finding of Aust and Huber (2001) that in a people-present/peopleabsent discrimination task, pigeons actually use categoryrelevant information (i.e., information contained in the target human figure) for classifying novel stimuli. In Test 2, the pigeons proved able to use at least some parts of the human body as cues for classifying a stimulus as a member of Class P. In Test 3, stimuli of Class NP that contained features that were normally typical properties of human figures did for the most part, lead to unambiguous peopleabsent classification.

In Test 1 , however, most of the size and silhouette test stimuli elicited people-absent responses. Obviously, training performances were guided by properties other than the general form or "outline" of a person. Likewise, reducing the absolute size of human figures, relative to the training stimuli, may have led to difficulty in discriminating relevant features in such "compressed" versions of people. The results of Test 1 also suggest that the pigeons were not able to exploit any features of the background that might have inadvertently made reliable class predictors when categoryrelevant information was not accessible or was insufficient for classification as people-present. In contrast to the targets, the backgrounds of the test stimuli did not, in the experimenters' best judgment, deviate in any systematic way from those of regular training stimuli of Class P. Thus, the only obvious differences between training and test stimuli were rooted in variations in the appearance of the depicted persons. By inference, if the pigeons made use of any simple background features, performance on the test stimuli should not have been affected so strongly.

Second, the results suggest that the pigeons made use of a compound of various stimulus properties and did not rely exclusively on only one or two salient features. Both target modifications investigated in Test 1 (small and silhouette) led to strong performance decrements, as compared with regular novel instances of Class $\mathrm{P}(\operatorname{trnP})$. Test 2 provided evidence that various parts of the human figure (hands; also, heads and trunks for some birds) were relevant for classifying a stimulus as a member of Class P.

Considering the complexity of the stimuli, it is hardly possible to pinpoint any critical features in Test 3 . It can, however, be said, although with some caution, that the likelihood of a stimulus's being classified as member of Class $P$ 
obviously depended on the number of features that the depicted nonhuman animals or objects were supposed to share with "people." As Medin (1989) put it, a stimulus "may have several typical properties of a category but not so many that it clearly qualifies for category membership" (p. 1471). Stimuli that showed animals wearing clothes (clothes worn) were more likely to provoke misclassification than pictures that showed either animals without clothes (ani$\mathrm{mal}$ ) or items of apparel that were not worn but were shown in isolation (clothes isolated). This suggests that being presented in combination with other categoryspecific features actually increased the predictive power of clothes, which is perfectly in keeping with similar findings by D'Amato and Van Sant (1988). For their monkeys, a nonperson slide containing a reddish patch was more likely to elicit classification errors if the color was a feature of an animal than if it was a feature of something inanimate. They concluded that, apparently, the conjoint features of red-patch/animal were an irresistible instance of the category that controlled the monkeys' classificatory behavior. Likewise, for pigeons, being an instance of Class $\mathrm{P}$ is probably not an all-or-nothing matter, but something additive - that is, a matter of more or less (Huber, 2001; Huber \& Lenz, 1993; Huber, Troje, Loidolt, Aust, \& Grass, 2000; Lea \& Harrison, 1978; Morgan, Fitch, Holman, \& Lea, 1976).

Third, the results suggest that the target-defining features were not equal in significance. Test 1 showed that target size was important (small), but even more critical was the presence of structural cues (silhouette). Similarly, some body parts in Test 2 were more effective cues than others. Hands/arms turned out to be highly predictive of Class P, trunks and heads were less predictive, and feet/legs, as well as skin color, did not make useful predictors of Class $\mathrm{P}$ at all. The reasons for this ranking are not quite clear. Training history and/or preexperience with human beings may be a partial account for such differences. For skin color, it turned out on closer inspection that skin color contained in the stimuli of Class $\mathrm{P}$ comprised a wide variety of different colors and shades. Furthermore, most stimuli in Class NP contained elements of colors similar to, or even identical with, those found in patches of human skin. ${ }^{1}$ We suggest that the considerable diversity in skin color-in strictly physical terms - may have been related to the pigeons' inability to use that feature as a discriminative cue. Since skin color was not a reliable, unequivocal characteristic of people-present stimuli, it did not make a good class predictor.

It is also noteworthy that the individual pigeons apparently did not rely on exactly the same parts of the target to the same extent. Whereas most or all birds "agreed" on hands/arms-in contrast to feet/legs and skin color-to make good predictors of Class $\mathrm{P}$, information conveyed by trunks and heads was used only by some birds. Thus, the internal feature lists built by the 6 birds did not appear to be exactly identical, although they showed some overlap.

How can the results of the present study be interpreted in the light of current categorization theories? Exemplar models originally rested on the assumption that the ability to categorize depends on remembering each instance or exemplar plus its category membership (Medin \& Schaffer, 1978). Such an account can well explain the ability to categorize familiar exemplars, such as the training stimuli in the present study. However, it has difficulty accounting for the pigeons' ability to generalize to novel instances. Modern formulations of the exemplar account, such as the configural theories of Pearce $(1987,1994)$ and Kruschke (1992), assume that the exemplar representation contains information about the features that are present on a particular trial and that, during training, there is generalization from one exemplar to another according to the degree of their similarity. These theories allow for the possibility that pigeons pay more attention to some features than to others and that the category-relevant features (i.e., those that occur more frequently in one class than in another) will exert greater control over responding than will category-irrelevant features (i.e., those that occur in both classes; see also Astley \& Wasserman, 1992).

However, our findings may also be explained by feature theory, which assumes that individual stimuli are assigned to categories on the basis of the features of which they are composed (see Huber, 2001, for an extended discussion). Membership in a category is thus determined by categorybased strategies such as a polymorphous class rule that combines a variety of features (D'Amato \& Van Sant, 1988; Huber \& Lenz, 1993; Huber et al., 2000; Lea, 1984; Lea \& Harrison, 1978; Lea \& Ryan, 1983). In fact, we have found evidence in support of the view that the pigeons relied on a collection of weighted category-relevant features, woven into a polymorphous class rule. (1) No single, isolated feature was found to be necessary or sufficient, but various target properties contributed incrementally to category membership (e.g., size, structure, hands, head, clothes, etc.). (2) Some features proved particularly central to the people-present category, insofar as some parts of the human figure (e.g., hands) made better predictors of Class $P$ than did others (e.g., trunks or heads). (3) Instances containing a large number of category-relevant features (e.g., clothes worn by animals) were more likely to be assigned as members of the respective category than were instances with only a few such features (clothes shown in isolation).

However, it appears that pigeons do not extract the same information from photographs and/or organize it in the same way as do humans. Our findings were similar to those of D'Amato and Van Sant (1988) with monkeys and Herrnstein and Loveland (1964) with pigeons. We found that the pigeons' principle of inclusion was obviously a bit more tolerant than ours - that is, they had a more permissive criterion. Especially given the findings of Test 3, one cannot be encouraged to infer complete equivalence of the categorizations of people and pigeons. Instead, they suggest a definite lack of isomorphy between human and pigeon target representation. At best, one may tentatively conclude that the two species are working with overlapping, but not precisely equivalent, categories (Herrnstein, 1990). 
What remains open is the question of whether our pigeons attended to organizational target properties or even integrated the multitude of target-defining features into a unified percept or, alternatively, whether they viewed the depicted human figures just as compounds of perceptual features whose unity approximated "people." The former would be in keeping with the results obtained by Brown and Dooling (1993), Kirkpatrick-Steger, Wasserman, and Biederman (1998), Steele (1990), Wasserman, KirkpatrickSteger, Van Hamme, and Biederman (1993), and Watanabe and Ito (1991), the latter with Cerella's particulate feature theory (Cerella, 1977, 1979, 1980, 1982, 1990). Further research efforts addressing this issue would certainly contribute to an even more comprehensive understanding of the way in which a pigeon solves a people-present/ people-absent discrimination task.

\section{REFERENCES}

Astley, S. L., \& Wasserman, E. A. (1992). Categorical discrimination and generalization in pigeons: All negative stimuli are not created equal. Journal of Experimental Psychology: Animal Behavior Processes, 18, 193-207.

Aust, U., \& Huber, L. (2001). The role of item- and category-specific information in the discrimination of people versus nonpeople images by pigeons. Animal Learning \& Behavior, 29, 107-119.

Bottuer, S. W., \& Hearst, E. (1979). Food delivery as a conditional stimulus: Feature-learning and memory in pigeons. Journal of the Experimental Analysis of Behavior, 31, 189-207.

Brown, S. D., \& Dooling, R. J. (1993). Perception of conspecific faces by budgerigars (Melopsittacus undulatus): II. Synthetic models. Journal of Comparative Psychology, 107, 48-60.

Cerella, J. (1977). Absence of perspective processing in the pigeon. Pattern Recognition, 9, 65-68.

Cerella, J. (1979). Visual classes and natural categories in the pigeon. Journal of Experimental Psychology: Human Perception \& Performance, 5, 68-77.

Cerella, J. (1980). The pigeons' analysis of pictures. Pattern Recognition, 12, 1-6.

CERElla, J. (1982). Mechanisms of concept formation in the pigeon. In D. J. Ingle, M. A. Goodale, \& R. J. W. Mansfield (Eds.), Analysis of visual behavior (pp. 241-249). Cambridge, MA: MIT Press.

Cerella, J. (1990). Shape constancy in the pigeon. In M. L. Commons, R. J. Herrnstein, S. M. Kosslyn, \& D. B. Mumford (Eds.), Quantitative analyses of behavior: Behavioral approaches to pattern recognition and concept formation (Vol. 8, pp. 145-163). Hillsdale, NJ: Erlbaum.

D' Амato, M. R, \& Van Sant, P. (1988). The person concept in monkeys (Cebus apella). Journal of Experimental Psychology: Animal Behavior Processes, 14, 43-55.

EDWARDS, A., \& Honig, W. K. (1987). Memorization and "feature selection" in the acquisition of natural concepts in pigeons. Learning \& Motivation, 18, 235-260.

Emmerton, J., \& Delius, J. D. (1980). Wavelength discrimination in the "visible" and ultraviolet spectrum by pigeons. Journal of Comparative Physiology, 141, 47-52.

GREENE, S. (1983). Feature memorization in pigeon concept formation. In M. L. Commons, R. J. Herrnstein, \& A. R. Wagner (Eds.), Quantitative analysis of behavior (Vol. 4, pp. 209-229). Cambridge, MA: Ballinger.

HeArst, E. (1978). Stimulus selection and feature selection in learning and behavior. In S. Hulse, H. Fowler, \& W. K. Honig (Eds.), Cognitive processes in animal behavior (pp. 51-88). Hillsdale, NJ: Erlbaum.

Herrnstein, R. J. (1985). Riddles of natural categorization. In L. Weiskrantz (Ed.), Animal intelligence (Vol. 7, pp. 129-144). Oxford: Oxford University Press, Clarendon Press.
HerrnsteIn, R. J. (1990). Levels of categorization. In G. M. Edelman, W. E. Gall, \& W. M. Cowan (Eds.), Signal and sense: Local and global order in perceptual maps (pp. 385-413). New York: Wiley.

Herrnstein, R. J., \& DE Villiers, P. A. (1980). Fish as a natural category for people and pigeons. In G. H. Bower (Ed.), The psychology of learning and motivation (Vol. 14, pp. 59-95). New York: Academic Press.

Herrnstein, R. J., \& Loveland, D. H. (1964). Complex visual concept in the pigeon. Science, 146, 549-551.

Herrnstein, R. J., Loveland, D. H., \& CAble, C. (1976). Natural concepts in pigeons. Journal of Experimental Psychology: Animal Behavior Processes, 2, 285-311.

Huber, L. (1994). Amelioration of laboratory conditions for pigeons (Columba livia). Animal Welfare, 3, 321-324.

Huber, L. (2001). Visual categorization in pigeons. In R. G. Cook (Ed.), Avian visual cognition. Retrieved from http://www.pigeon.psy.tufts. edu/avc/.

Huber, L., \& Aust, U. (2001). The relevance of evolution, species comparison, color, and categorization for the object identity problem. Cahiers de Psychologie Cognitive/Current Psychology of Cognition, 20, 101-108.

Huber, L., \& Lenz, R. (1993). A test of the linear feature model of polymorphous concept discrimination with pigeons. Quarterly Journal of Experimental Psychology, 46B, 1-18.

Huber, L., Troje, N. F., Loidolt, M., Aust, U., \& Grass, D. (2000). Natural categorization through multiple feature learning in pigeons. Quarterly Journal of Experimental Psychology, 53B, 341-357.

Jenkins, H. M., \& Sainsbury, S. R. (1969). The development of stimulus control through differential reinforcement. In N. J. Mackintosh \& W. K. Honig (Eds.), Fundamental issues in associative learning (pp.123-161). Halifax, Nova Scotia: Dalhousie University Press.

Jenkins, H. M., \& SAInsbury, R. S. (1970). Discrimination learning with the distinctive feature on positive or negative trials. In D. Mostovsky (Ed.), Attention: Contemporary theory and analysis (pp. 239-273). New York: Appleton-Century-Crofts.

KirkPATRICK-Steger, K. (2001). Object recognition. In R. Cook (Ed.), Avian visual cognition. Retrieved from http://www.pigeon.psy.tufts. edu/avc.

KirkPatrick-Steger,K., Wasserman, E. A., \& Biederman, I. (1998). Effects of geon deletion, scrambling, and movement on picture recognition in pigeons. Journal of Experimental Psychology: Animal Behavior Processes, 24, 34-46.

KRUSCHKE, J. K. (1992). ALCOVE: An exemplar-based connectionist model of category learning. Psychological Review, 99, 22-44.

LEA, S. E. G. (1984). In what sense do pigeons learn concepts? In H. L. Roitblat, T. G. Bever, \& H. S. Terrace (Eds.), Animal cognition (pp. 263276). Hillsdale, NJ: Erlbaum.

Lea, S. E. G., \& Harrison, S. N. (1978). Discrimination of polymorphous stimulus sets by pigeons. Quarterly Journal of Experimental Psychology, 30, 521-537.

LEA, S. E. G., \& Ryan, C. M. E. (1983). Feature analysis of pigeons' acquisition of concept discrimination. In M. L. Commons, R. J. Herrnstein, \& A. R. Wagner (Eds.), Discrimination processes (Vol. 4, pp. 263 276). Cambridge, MA: Ballinger.

Malott, R. W., \& Siddall, J. W. (1972). Acquisition of the people concept in pigeons. Psychological Reports, 31, 3-13.

Manabe, K., \& Kawashima, T. (1982). The feature-positive effect based on positional discrimination in pigeons. Annual of Animal Psychology, 31, 89-102.

McIlvane, W. J., Serna, R. W., Dube, W. V., \& Stromer, R. (2000). Stimulus control topography coherence and stimulus equivalence: Reconciling test outcomes with theory. In J. C. Leslie \& D. Blackman (Eds.), Experimental and applied analysis of human behavior (pp. 85110). Reno, NV: Context Press.

Medin, D. L. (1989). Concepts and conceptual structure. American Psychologist, 44, 1469-1481.

Medin, D. L., \& Schaffer, M. M. (1978). A context theory of classification learning. Psychological Review, 85, 217-238.

Morgan, M. J., Fitch, M. D., Holman, J. G., \& Lea, S. E. G. (1976). Pigeons learn the concept of an "A." Perception, 5, 57-66.

Pace, G. M., McCoy, D. F., \& Nallan, G. B. (1980). Feature-positive 
and feature-negative learning in the Rhesus monkey and pigeon. American Journal of Psychology, 93, 409-427.

Pearce, J. M. (1987). A model for stimulus generalization for Pavlovian conditioning. Psychological Review, 94, 61-73.

Pearce, J. M. (1994). Similarity and discrimination: A selective review and a connectionist model. Psychological Review, 101, 587-607.

Pearce, J. M. (1997). Animal learning and cognition. An introduction. Hove, U.K.: Psychology Press.

Roberts, W. A., \& MaZmanian, D. S. (1988). Concept learning at different levels of abstraction by pigeons, monkeys, and people. Journal of Experimental Psychology: Animal Behavior Processes, 14, 247-260.

SAINSBURY, R. S. (1971). Effect of proximity of elements on the featurepositive effect. Journal of the Experimental Analysis of Behavior, 16, 315-325.

SAInSBURY, R. S., \& Jenkins, H. M. (1967). Feature-positive effect in discrimination learning. Proceedings of the Annual Convention of the American Psychological Association, 2, 17-18.

SChrier, A. M., \& BRADY, P. M. (1987). Categorization of natural stimuli by monkeys (Macaca mulata): Effects of stimulus set size and modification of exemplars. Journal of Experimental Psychology: Animal Behavior Processes, 13, 136-143.

Siegel, R. K., \& Honig, W. K. (1970). Pigeon concept formation: Successive and simultaneous acquisition. Journal of the Experimental Analysis of Behavior, 13, 385-390.

SteEle, K. M. (1990). Configural processes in pigeon perception. In M. L. Commons, R. J. Herrnstein, S. M. Kosslyn, \& D. B. Mumford (Eds.), Quantitative analyses of behavior: Behavioral approaches to pattern recognition and concept formation (Vol. 8, pp. 111-125). Hillsdale, NJ: Erlbaum.

Troje, N. F., Huber, L., Loidolt, M., Aust, U., \& Fieder, M. (1999). Categorical learning in pigeons: The role of texture and shape in complex static stimuli. Vision Research, 39, 353-366.

Vaughan, W. J., \& Greene, S. L. (1984). Pigeon visual memory capacity. Journal of Experimental Psychology: Animal Behavior Processes, 10, 256-271.

Wasserman, E. A., Kirkpatrick-Steger, K., Van Hamme, L. J., \& Biederman, I. (1993). Pigeons are sensitive to the spatial organization of complex visual stimuli. Psychological Science, 4, 336-341.

Watanabe, S., \& ITo, Y. (1991). Discrimination of individuals in pigeons. Bird Behavior, 9, 20-29.

Watanabe, S., Lea, S. E. G., \& Dittrich, W. H. (1993). What can we learn from experiments on pigeon concept discrimination? In H. P. Zeigler \& H.-J. Bischof (Eds.), Vision, brain, and behavior in birds (pp. 351-376). Cambridge, MA: MIT Press.

\section{NOTE}

1. Since it is hardly possible to assess how pigeons experience colors on the subjective level (see, e.g., Emmerton \& Delius, 1980), these investigations were based on objective, physical, parameters, such as RGB values and brightness.

(Manuscript received September 25, 2001; revision accepted for publication February 14, 2002.) 